\title{
O ESTADO NOVO COMO PROPOSITOR DA NAÇÃO: O TEMA DO REGIONALISMO PERPASSANDO A IDEOLOGIA DO REGIME ENTRE 1938 E 1945
}

\section{THE NEW STATE AS PROPOSER OF NATION: THE THEME OF REGIONALISM PERMEATING THE REGIME'S IDEOLOGY BETWEEN 1938 AND 1945}

\author{
Weslley Luiz de Azevedo Dias ${ }^{1}$ \\ ${ }^{1}$ Universidade do Estado do Rio de Janeiro, Instituto de Estudos Sociais e Políticos, Brasil, e- \\ mail:weslleyaadias@gmail.com
}

\begin{abstract}
ARTICLE INFO
Article history:

Received 2019-07-15

Accepted 2019-12-14

Available online 2019-12-14

Palavras-chave: Pensamento Político. Estado Novo. Regionalismo. Localismo.

Keywords: Political Though. New State. Regionalism. Localism.

RESUMO. O tema do regionalismo assumiu importância crucial ao longo do desenvolvimento do Pensamento Político Brasileiro. Como tópico constante nas discussões de várias obras, tal assunto passou a fazer parte, não somente, de um cânone, como também de um imaginário total de nacionalidade. Durante o Estado Novo, vários autores dedicaram-se a uma tentativa de compreensão da gênese de questões cruciais para o desenvolvimento da nação. Nesse sentido, será objetivo deste trabalho compreender a maneira como seus textos expressaram a questão do regionalismo no Brasil e, dessa forma, examinar as disposições sobre o assunto durante o Estado Novo. Utilizaremos obras de alguns arautos do regime, como Oliveira Viana, Manuel Duarte, Francisco Campos e Azevedo Amaral. Outras serão dos intérpretes oficiais do regime, como Almir de Andrade e o próprio Getúlio Vargas. Para efeito comparativo, trabalharemos também alguns dos opositores do governo, em busca de talvez uma postura diversa em relação ao tema. Para tal intento, nos valeremos de uma exploração contextualista nos moldes de John Pocock como base interpretativa para os diálogos da época.
\end{abstract}

\begin{abstract}
The theme of regionalism assumed crucial importance throughout the development of Brazilian Political Thought. As a constant topic in the discussions of multiple works, this subject has become part, not only of a canon, but also of an entire imaginary about nationality. During the New State, many authors were dedicated to understand the geneses of crucial issues to the development of the nation. Then, the objective of this work is to understand how their texts expressed a preoccupation about regionalism in Brazil and, so, examine the different point of views about this subject. In order to do so, the analyses contains the works of some regime's heralds, like Oliveira Viana, Manuel Duarte, Francisco Campos and Azevedo Amaral. The other group is formed by the official interpreters of the government's aims, like Almir de Andrade and Getúlio Vargas himself. For this, we will use a contextualist approach, based in John Pocock's work, in order to examine the dialogues of that time.
\end{abstract}




\section{Introdução}

Algumas características determinaram o processo de desenvolvimento da cultura e sociedade brasileiras. Uma delas pode ser relacionada à sua grandeza territorial. Por aqui, circunscrições regionais atingiram dimensões impressionantes, em relação aos das metrópoles europeias. Com exceção de alguns vizinhos, as distâncias e insulamentos, devidos à magnitude continental da colônia, operaram as mais diversas variações quanto aos padrões de tradição de cada localidade. Neste cenário, o Estado Brasileiro se veria de diversas maneiras provocado a interferir na questão regional do país.

O sentido desta discussão se iniciaria a partir de uma visão dicotômica da nacionalidade. Euclydes da Cunha seria o primeiro a mencionar a existência de "dois Brasis" em Da Independência à República de 1900 (SANTOS, 2017), no que foi seguido por intelectuais como Martins de Almeida com sua noção de institutos de "superfície" e "fundo", ideia explorada em Brasil Errado (1932). O autor estipularia uma ordem de legitimidade e autenticidade entre as duas formas. O "fundo", rural, seria o verdadeiro representante da realidade nacional. Esta dicotomia acabou gerando ramificações em diversos campos de ação humana, tendo um peso ainda maior em questões de cunho político.

Os anos de 1930 foram marcados por diversas obras preocupados em corrigir os supostos vícios alimentados durante os anos da Primeira República. O autoritarismo e fortalecimento da centralidade da União acabaram sendo fundamentais em meio a uma tônica de elogio ao poder do Estado. As distorções causadas pelo caos no mundo da política durante o início do século acabariam reverberando nos autores, que traduziram estas preocupações em obras cada vez mais avessas aos interesses regionais sobrepostos às políticas nacionais. Nesse sentido, iremos tratar no presente trabalho sobre como os nomes relacionados ao Estado Novo demonstraram esta disposição negativa a partir de sua mobilização do tema do regionalismo.

Para entender a utilização do tema regional, teremos que dispor de uma metodologia contextualista que nos permita compreender como tais textos se inseriram na linguagem política da época. Para além disso, deveremos ter cuidado redobrado com o trato da questão, haja visto que os conceitos relacionados à ideia regional se apresentam de modo fugidio ao longo de todas as obras. Poderemos observar como, ao longo destes textos, certos significados apresentaram-se sob significantes diversas. Os termos que geralmente acompanham a questão regional nessa literatura são localismo, caudilhismo, provincialismo, política facciosa, dentre outros. Todos indicando o sentido de abordagem da pauta por parte do Regime.

Também deveremos separar a postura em relação ao regionalismo cultural de uma crítica ao partidarismo faccioso, tão forte durante o Estado Novo e presente em toda literatura não liberal produzida durante os anos 30 . Outro ponto que não pode ir a reboque em nossa 
análise será a noção do fenômeno da regionalidade como algo exclusivamente brasileiro. Mesmo os Estados Unidos, grande modelo americano da época, já haviam passado por uma escalada nos conflitos políticos que possuía no elemento regional uma de suas principais causas. Compreender a nacionalidade então nos implica em compreender a noção de região.

Finalmente, neste artigo, trataremos das obras situadas entre os anos de 1937 e 1945, pertencentes a um cânone que pode ser considerado de ideólogos do Estado Novo. Em um primeiro momento, trataremos dos nomes envolvidos com os preceitos do que viria a se tornar uma ideologia estado-novista, mas que não necessariamente faziam parte do governo. Eles serão Oliveira Viana, Manuel Duarte, Azevedo Amaral e Monte Arrais, todas figuras conectadas ao regime. Em um segundo ponto, trabalharemos dois nomes que consideramos centrais na realização do ímpeto ideológico do regime. Tais serão Almir de Andrade e o próprio presidente, Getúlio Vargas. Como figuras centrais do regime estes dois guardam noções mais diretas

\section{Grupo estado-novista: aparolecrítica ao regionalismo em um contexto autoritário}

Em The Reconstruction of Discourse: Towards the Historiography of Political Thought, John Pocock (1981) tratou de sua abordagem da reconstituição do pensamento político como discurso. Para ele, a categoria se definiria como uma sequência de atos de fala performados por agentes em determinada estrutura social, contexto histórico e linguagem política.

Assim como Quentin Skinner, ele partiu da divisão da linguagem entre locucionária, ilocucionária e perlocucionária. Por sua vez, este outro autor da célebre Escola de Cambridge, retira essa divisão da Filosofia da Linguagem de John Austin (1990). Nos três, o aspecto locucionário se aplicaria à língua empregada de acordo com as regras sintáticas para transmitir uma mensagem. Já o ilocucionário serviria para categorizar o seu uso com a intenção de transmitir determinada mensagem e ao mesmo tempo realizar uma ação. $O$ último aspecto, o perlocucionário, se definiria pela busca a partir da linguagem de gerar determinado efeito em seu receptor. Skinner (1969) e Pocock (1981) destacam o último tipo para entender as ideias políticas como forma de intervir e transformar a realidade. Entretanto, o segundo se preocupa mais diretamente em inserir estes atos de fala dentro de seu contexto histórico mais amplo, enquanto o primeiro tende a enfatizar o autor em sua sincronia, dando ênfase maior para o intelectual em si, que costuma ser sua unidade de análise. Nos aproximando mais de John Pocock, teremos como unidade de análise deste trabalho o texto do autor enquanto discurso inserido em uma linguagem.

Para John Pocock, a ação linguística dos indivíduos parte do vocabulário disponível na estrutura do seu contexto histórico. A partir disso, a ação deles buscaria modificar essa situação em favor do agente. Em O conceito de linguagem e o métier d'historien (POCOCK, 
2003), o autor utiliza termos da linguística para marcar que os atos de fala seriam uma parole inseridos em uma langue, que é o seu contexto. Então, a partir de John Pocock, podemos considerar o estudo dos discursos políticos como a busca de compreender o diálogo entre o autor e seus correspondentes no qual cada um deles pode explorar os recursos linguísticos disponíveis e performar atos de fala, a partir dos padrões de comunicação que lhes são impostos. (POCOCK, 1990, p. 963). Nesta abordagem, o texto é considerado como uma estrutura formal na qual uma unidade intelectual foi imposta pelos atos de fala do seu autor, que, por sua vez, está dentro da história. (POCOCK, 1990, p. 977). No estudo que aqui pretendemos explorar, regionalismo é um conceito inserido em uma linguagem autoritária hegemônica entre os anos de 1930 e 1945, rediviva de tempos em tempos. Na longa duração, tal perspectiva está conectada à perene discussão sobre a formação Nacional do país.

Nesta empreitada, nos valeremos desta metodologia inspirada no contextualismo linguísto de J. G. A. Pocock. Isso permitirá uma abordagem dos escritos apoiadores do Regime que fuja de uma hermenêutica mais redundante. Como textos de seu tempo, os escritos desses autores representaram as apropriações que seus autores tiveram dos fatos práticos do presente e passado. Esse tipo de abordagem histórica do pensamento social e político nos ajudará a compreender melhor como os livros se relacionam tanto com a realidade contemporânea, quanto entre si (POCOCK, 2003).

Outras influências teórico-metodológicas do trabalho são a História dos Conceitos de Reinhart Koselleck e o Contextualismo Linguístico de Quentin Skinner. Os dois autores são tratados como aproximáveis a partir da análise de Marcelo Jasmin (2005), que os vê como complementares, já que, juntos, ajudam a pensar as dimensões diacrônicas e sincrônicas das ideias políticas. Nesta pesquisa, o primeiro autor nos permite, junto com as abordagens teóricas de Wanderley Guilherme dos Santos (1970) e Christian Lynch (2016), pensar o conceito de Regionalismo em uma duração mais ampla no tempo. Deste modo, pode-se perceber a história do conceito como referente ao que Mark Bevir (2008) chama de tradição.

\section{O prelúdio do Regime e as fundações do sentimento anti-regionalista}

Como dito anteriormente, nesse momento, trataremos de dois tipos de produção textual, discutindo tanto obras que lidaram com alguns dos fundamentos do regime quanto as que foram mais diretamente relacionadas à sua sustentação. Desse modo, não poderíamos deixar de iniciar a presente analise por outro que não o nome de Francisco José de Oliveira Viana (1883-1951). Dentre os principais autores do Pensamento Político e Social Brasileiro é difícil omitir o jurista fluminense. Dono de um dos mais vastos acervos bibliográficos na história intelectual brasileira, este se tornaria uma das mais importantes fontes de fundamentação ideológico para o governo de Getúlio Vargas entre 1930 e 1945. Sendo um dos principais nomes de uma tradição que pode ser considerada estatista e centralizadora, Oliveira Viana 
acabaria sendo o principal provedor de horizontes reflexivos para o Regime instaurado em 1937.

Em O Idealismo da Constituição, publicado originalmente em 1939, ano inicial do Estado Novo, o autor abordou sobretudo os equívocos da história constitucional brasileira e mundial. Tendendo a uma visão mais autoritária, no sentido mais próximo à contrariedade do liberalismo do que próximo ao totalitarismo, o texto abarca a trajetória das balizas constitucionais brasileiras desde a independência, prestando atenção redobrada no modo de organização nacional engendrado por tais dispositivos jurídicos. No entanto, mesmo textos de enfoque constitucional, acabaram apresentando traços da postura do regime enquanto aos regionalismos brasileiros.

A preocupação central no texto de Oliveira Viana parece ser com o desenho tomado pela organização da nação a partir dos dispositivos constitucionais ao longo de sua história e é nesse ponto que incide a abordagem do tema. Inicialmente, pode ser percebida uma clara disposição centralizadora, que acaba culminando em ampla crítica ao regionalismo. Este seria uma ameaça ao ideal de nação, esmaecendo a autoridade da União (VIANA, 1939, p. 127). Sua crítica ao regionalismo dita o tom da crítica do regime ao seu viés mais político. Assim sendo, a questão seria de que modo tal fenômeno desembocou na distribuição de prerrogativas do poder central para as regiões.

A luta principal seria a do Estado contra o Regionalismo Político exacerbado e o pior dos mundos seria aquele no qual o império da União sobre os estados se visse ameaçado, ou seja, onde as províncias mandassem e o centro obedecesse. $O$ ataque de Oliveira Viana ao poder regional, utilizou a ideologização das facções regionais como um dos maiores empecilhos e malfeitos à organização nacional (VIANA, 1939, p. 150). Desse modo, o medo em relação aos Estados seria um ponto frequente em sua crítica à República Velha. Mesmo assim, o governo central deveria ser desapaixonado, do ponto de vista ideológico, atendendo a um pragmatismo adequado às condições impostas pela realidade nacional.

A crítica ao fator regional ainda assumiria uma camuflagem dificilmente contornável; um ataque aos clãs territoriais, ainda fortemente poderosos em algumas partes do país (VIANA, 1939, p. 197). De fato, a influência do mandonismo local na política nacional constituiu uma das maiores mazelas ao exercício da organização nacional sob o ponto de vista dos apoiadores do Estado Novo. O autor ainda utiliza o baixíssimo índice de renovação das bancadas estaduais como uma ferramenta crítica contra as províncias. Sendo assim, o mandonismo local nordestino se firmaria ainda mais como um elemento claro de desagregação da nacionalidade.

Com a sobre-representação de interesses estaduais e, em última instância, regionais, problemas de caráter localizado assumiram a forma de interesse nacional. Para Oliveira Viana 
e alguns de seus sucessores, a principal mazela que a construção da nação poderia vivenciar seria o a submissão do poder da União aos estados (VIANA, 1939, p. 271).

Em Doutrina contra doutrina texto de 1940, Manuel Duarte (1883-1957), membro de uma tradicional família pecuarista do Rio Grande do Sul, também adotaria uma posição um tanto cética quanto ao caráter benéfico das divisões regionais. Apesar de seu passado vinculado à defesa de certos interesses específicos dos estados, o autor apontaria conteúdos prejudiciais nessa estrutura. Diferentemente da obra de Oliveira Viana, o tema do regionalismo foi pouquíssimo citado na obra do autor

Em mais de 160 páginas, Doutrina contra doutrina abordaria tal questão em apenas quatro oportunidades. Primeiramente, como crítica ao espírito de "clã", chamando atenção para sua nocividade em relação ao ideal unitário nacional (DUARTE, 1940, p. 118). Sobre nossas diferenciações regionais o autor completa:

o desenvolvimento fragmentário da escassa população distribuída numa vastíssima área, portanto sem continuidade demográfica, retardou a associação maior, fechou no âmbito de dadas regiões, interesses que deveriam ser gerais e exteriorizou-se, assim, em circunscrições territoriais que só não se fizeram rivais e talvez inimigas, por um milagre das influências telúricas que a todos aconselhavam e apontavam um idêntico destino. (DUARTE, 1940, p. 121)

Mais uma vez, a nação estaria sendo constituída apesar de seus regionalismos. Segundo o autor, teríamos nos tornado uma nação acantonada, localizada, regionalizada e sem a devida integração em um todo nacional (DUARTE, 1940, 121). No entanto, é nesse momento que a crítica ao regionalismo exacerbado dá lugar a uma crítica aberta aos fatores políticos embutidas neste tipo de dinâmica. Para Manuel Duarte, a questão central e mais nociva em meio a esse espírito clânico seria a sua tradução política na forma de um espírito de partido. Este seria, a seu ver, o grande mal vigorante já nas instituições monárquicas, mas que ganharia potência redobrada na jovem república de 1889. O Brasil estaria dessa forma submetido aos interesses da terriola, estes contrários aos interesses da comunhão nacional.

Podemos perceber até esse ponto, a forte preocupação destes primeiros autores com a questão da organização nacional. Oliveira Viana, o grande nome dessa corrente de ensejo ao Estado Novo, serve para nos mostrar a preocupação com a eliminação desse potencial. Em seu livro, Direito do Trabalho e Democracia Social: O problema da incorporação do trabalhador no estado, o autor opera conexões muito recorrentes no período no vocabulário tanto dos críticos ao regionalismo quanto aos seus defensores. Apesar de ter sido uma obra voltada para o posicionamento do trabalhador dentro de uma nova ideologia e práxis estatal, o livro também abordaria o tema do regionalismo. Nesse sentido, no que tange o trabalhador brasileiro, todos os problemas nacionais deveriam ser federalizados, assim eliminando o horizonte provincial maléfico na inserção de uma pauta trabalhista estadual (VIANA, 1951, p. 
101-102). É interessante notar que o tema da raça aparece sendo tratado de modo bastante amplo na obra, pensando em sua interseção com a questão do trabalho.

A obra de Francisco Campos (1891-1968) também surge como uma importante contribuição para nossa reflexão a respeito da abordagem do tema do regionalismo. Como um dos autores da Constituição de 1937, considerada o baluarte da construção estado novista, e a sua participação na elaboração do Ato Institucional Número Um, Al-1, o jurista seria para sempre associada às correntes autoritárias brasileiras do médio século $\mathrm{XX}$.

A crítica do autor à influência regional aparece pela primeira vez em $O$ Estado Nacional. Campos aborda a questão da constituição da Assembleia Nacional, mencionando a necessidade de controlar suas fileiras, de modo a combater a sobre-representação regional (CAMPOS, 2001, p. 94). Entendendo que o regionalismo atende a certas ambições deletérias à unidade nacional (CAMPOS, 2001, p. 108), o autor prossegue fazendo uma denúncia das facções regionais (CAMPOS, 2001, p. 117-118). A realização da nacionalidade, dessa forma, seria inversamente proporcional às "crônicas regionais" e o combate a tais tendências deveria ser um dos maiores ímpetos necessários ao novo regime.

A tendência à uniformização nacional não foi prerrogativa exclusiva às empreitadas autoritárias brasileiras. Desde o totalitarismo alemão ou italiano até o comunismo fechado de Cuba ou União Soviética, tais regimes sempre optaram por um ideal de união que corrobore seu poder centralizado e mitigue os fatores internos de diferenciação. Nada leva um governo autoritário a crer que, por exemplo, um bávaro tenha algum tipo de solidariedade incontornável com um cidadão de Hamburgo.

O tema da uniformidade do construto nacional ganha relevo ainda maior em $O$ Estado Autoritário e a Realidade Nacional. A suposta ausência de um povo adequado aos desafios do desenvolvimento e progresso brasileiro já eram paroles comuns nos debates do pensamento político, tendo alguns autores se posicionado à favor de um perfil miscigenado, como Gilberto Freyre, e outros mais voltados à correção desse quadro populacional, como Oliveira Viana, querendo substituir os influxos do país por um novo caldeamento europeizado. Neste sentido, seria ingenuidade nossa imaginar que a literatura de suporte ao Estado Novo passasse incólume à esse tema.

Seguindo a toada dos trabalhos de outros médicos ${ }^{1}$ que se envolveram com o tema da questão racial no país ${ }^{2}$, nesta obra, a imigração branca europeia seria um imperativo

\footnotetext{
${ }^{1}$ Os estudos iniciais sobre algo referente a relações raciais no Brasil foram marcados pela presença de médicos entre seus principais nomes. O maior deles talvez tenha sido Nina Rodrigues, que realizou pesquisas variadas e pioneiras no país. No entanto, a postura de Azevedo Amaral em relação ao tópico da questão racial no contexto dos anos 40 permanece sendo curiosa, devido à valorização da mestiçagem praticada pelo Estado Novo. Além disso, sua posição destoava, em grande medida, do próprio racialismo corrente na época.
}

${ }^{2}$ Azevedo Amaral foi um dos participantes do I Congresso Brasileiro de Eugenia em 1929 
imediato e urgente ao indispensável desenvolvimento, configurando uma verdadeira "urgência" nacional (AMARAL, 2002, p. 135). Mas não divagamos de modo infundado pelo conteúdo racialista da obra de Azevedo Amaral (1881-1942). Nosso intuito é tentar tocar no tema da uniformização e como estes autores operaram sob uma chave de uniformização nacional. Esta pode tomar formas das mais diversas, mas no que compete à recente exploração a que mais nos interessa é a questão da regionalidade.

A obra segue o mesmo padrão crítico ao poder regional durante a Primeira República. Mas talvez seja este o texto com avanços mais contundentes em termos de uma crítica ao regionalismo propriamente político. Azevedo Amaral ainda chama atenção para os perigos que o regionalismo separatista representou durante a regência, com o risco de dissolução nacional (AMARAL, 2002, p. 19). Agora surge a razão de pensar o tema da regionalidade sob a mesma chave do racialismo do autor, pois quando este discute as mazelas do Império vê no ímpeto abolicionista um dos principais elementos disruptivos da unidade nacional, elegendo Cotegipe como seu grande exemplo de estadista do século XIX (AMARAL, 2002, p. 20). A permissividade imperial com as tendências regionalistas deveria, dessa forma, servir de lição para o novo regime instaurado pela Constituição de 1937.

Em Getúlio Vargas Estadista (1941), na fase intermediária do regime, com as potências do Eixo ainda sob vantagem no palco europeu, Azevedo Amaral demonstrou novamente sua preocupação com uma postura telúrica em relação à paternidade da nação (AMARAL, 1941, p. 169). No capítulo intitulado $A$ ideia nacional, o autor ainda caracterizaria o nacionalismo de sua contemporaneidade como um tripé básico, constituído pelo instinto da terra e instinto da raça como bases de uma estrutura moral do patriotismo (AMARAL, 1941, p. 156).

Já em Os grandes problemas nacionais, coletânea de 1942 composta por diversos opúsculos voltados aos temas do dia para o regime ${ }^{3}$, Azevedo Amaral assinou um pequeno texto intitulado Ordem e paz brasileiras. Nele, o fundador do desenvolvimentismo redivivo abordou de modo geral o imperativo de paz interna, a importância de um ideal de unidade e a relevância do progresso moral e material representando pela instauração do Estado Novo (AMARAL, 1942)

Podemos identificar em Azevedo Amaral, uma das mais consistentes investidas contra o que o autor chamaria de "particularismos regionalistas" que mitigavam a construção de uma ideia nacional. A esta questão se somaria novamente uma crítica ao federalismo da Primeira República e a constatação de seu risco para o Brasil (AMARAL, 1942, p. 24). O Estado Novo não poderia ter a mesma permissividade da Antiga República. Esta haveria condicionado o enfraquecimento da nação através de erros consecutivos em relação aos exorbitantes

\footnotetext{
${ }^{3}$ Organizada pelo Departamento de Imprensa e Propaganda (DIP)
} 
sentimentos regionalistas. Sendo assim, na República Velha, a nação teria convivido com os mais nocivos "egotismos regionalistas" (AMARAL, 1942, p. 22-24).

Apesar das possíveis censuras contemporâneas e posteriores à publicação destes três textos abordados, Azevedo Amaral pode ser considerado um dos autores mais coerentes do ponto de vista interno em sua crítica à ameaça regionalista. No conjunto, toda sua crítica à fragmentação política e disputa centrífuga durante a história brasileira serve não só de base para seu abastecimento do regime do Estado Novo, mas também para seu próprio horizonte reflexivo.

Por último, analisaremos a obra de mais um dos autores que podem ser considerados arautos do Estado Novo. Este seria Raimundo Monte Arrais (1882-1865), filho de uma família tradicional cearense e deputado pelo mesmo estado de 1935 à 1937 . Sua figura seria essencial durante o período ditatorial através da chefia na seção de censura do Departamento de Imprensa e Propaganda (DIP). Apesar de assinar diversas obras, nos dedicaremos a $O$ Estado Novo e suas diretrizes, pois este foi o texto que maior relação guardou com a sua contribuição ao Estado Novo.

Apesar de ser um texto voltado, sobretudo, para questões constitucionais, podemos constatar que o tema regional não deixa de figurar entre os assuntos tratados. Assim como os demais autores apresentados até o momento, sempre que o tema da regionalidade surgiu, seria sob um viés negativo, criando empecilhos à correção da nação. $O$ autor inclusive chega a fazer referência a uma redenção de regiões consideradas problemáticas, como o Nordeste e o Sul. O ímpeto de fortalecimento do país deveria atender desse modo à superação de uma estrutura na qual agregados puramente regionalistas impediam a evolução de um Estado lidimamente nacional (ARRAIS, 1938, p. 43).

Neste texto encontramos uma franca declaração de guerra contra certas independências locais. Ao tratar da Inglaterra, Monte Arrais afirmaria que apenas após a supressão dos baronatos regionais a construção de um estado nacional sob a égide normanda pôde se realizar (ARRAIS, 1938, p. 45). No Brasil, o espírito desagregador engendrado pelo sistema de capitanias não pôde ser devidamente corrigido (ARRAIS, 1938, p. 47. Nossa necessidade histórico-social se faria, desse modo, no sentido da centralização. $O$ autor inclusive chamaria atenção para inconstitucionalidade na ostentação de bandeiras, emblemas e símbolos de cunho regional, alertando para a necessidade de se construir uma mentalidade das massas no país (ARRAIS, 1938, p. 49-50). Toda essa preocupação se deveria ao fato de que o "caudilhismo regional" seria uma das ameaças mais ostensivas à unidade nacional, juntamente aos particularismos locais que esta forja.

O elemento que mais chama atenção nos textos tratados é a extrema coerência desta linguagem contextual vigente na época entre o grupo de apoiadores do regime. Além disso, os lances, usando-nos de uma concepção pocockiana, parecem ser extremamente 
semelhantes. Estes atos teriam o mesmo sentido definidor de uma crítica ao regionalismo, mas através de suas prerrogativas políticas. No entanto, é uma de nossas teses que tais utilizações do termo regionalismo sob formas propriamente do debate político, como mandonismo e localismo, acabaram gerando efeitos na constituição de um imaginário negativo sobre regionalidade fora do centro arbitrário de poder, sobretudo voltado às regiões menos ricas e menos brancas.

\section{A postura oficial do Regime: os arquitetos do tratamento político à questão regional}

Após tratarmos dos textos de figuras ligadas ao Regime, neste momento abordaremos as palavras de dois dos principais nomes do Estado Novo. Como fizemos referência anteriormente, o primeiro deles será Almir de Andrade, talvez uma das pessoas mais próximas à Getúlio Vargas durante seu primeiro período no poder. Em um segundo momento, analisaremos uma obra assinada pelo próprio presidente, intitulada As diretrizes da nova política do Brasil.

Almir Bonfim de Andrade (1911-1991) pode ser considerado um dos principais ideólogos do Estado Novo, juntamente com Francisco Campos e Azevedo Amaral. No entanto, suas contribuições para o regime extrapolaram os limites da influência propriamente intelectual e alcançaram a dimensão da realização do ideal estado novista. Almir de Andrade talvez tenha sido a mais bem-sucedida figura do Estado Novo a reunir em seu entorno nomes não comprometidos com o regime. Isto deveu-se em parte à sua abordagem única sobre as condicionantes e exigências de uma ideologia do governo. Como teórico, optou pela temática cultural como chave de análise das necessidades da nação, sendo, nesse sentido, o maior cronista cultural tanto do grupo tratado, quanto do período de 1937 à 1945.

Em 1940, o autor dedica o livro Força, Cultura e Liberdade: Origens históricas e tendências atuais da evolução política do Brasil à memória de seu pai, o Capitão de Mar e Guerra Francisco Bonfim de Andrade. Esta é a obra que consegue de modo mais amplo, compatibilizar o Estatismo, típico da ideologia do Estado Novo, com o Culturalismo que corria por fora dos quadros do regime. Desse modo, não seria de se admirar que Almir de Andrade estivesse tão próximo de Gilberto Freyre e Graciliano Ramos, dois dos nomes mais influentes deste seguimento.

O tema do regionalismo surge aqui no enclave entre o Estado Novo e uma representação de seu significado para a índole e cultura brasileiros. O autor inclusive iria se referir a uma necessária "plasticidade do governo", em clara alusão ao conceito de Freyre. Tudo isso para dar a entender que o Estado, tal qual a Sociedade, deveria ser maleável o suficiente para se adaptar aos fluxos e contrafluxos culturais característicos de nossa nacionalidade. Para Almir de Andrade, a nação seria o epíteto da cultura e dessa forma, nossa conformação estatal deveria estar condicionada a essa mesma cultura. No entanto, de modo 
compreensivo e não subordinado. Nosso nacionalismo deveria se tratar de viver plenamente como somos e de acordo com nosso caráter cultural específico.

Em relação ao nosso regionalismo, o Brasil teria conseguido alcançar um estado de unidade cultural e linguística que o elegeria entre os países americanos que mais êxito encontraram quanto à construção de uma nacionalidade (ANDRADE, 1940, p. 36). Essa cultura, como verdade profunda, não poderia ser contida pelo Estado e caberia a este compreender tal fenômeno. O Estado Novo estaria em conformidade com as necessidades da cultura social do país. A obrigação de respeitar a cultura seria essencial, pois esta produziu as tradições responsáveis pela alma da nação.

Ao tratar da relação entre governantes e governados, a postura do autor quanto à adequação estatal passa por uma necessidade de alteração dessa realidade. Não uma alteração desrespeitosa, mas uma que faça minimamente valer o imperativo da centralidade da União. Esta cautela se justifica, pois nenhuma sociedade "[...] muda de cara como se muda de máscara. Uma mentalidade social nova não se improvisa num dia, nem se impõe pela força [...]" (ANDRADE, 1940, p. 103). Desta forma, o drama que estaria à frente da nação seriam as distorções causadas pela nossa "[...] mentalidade política localista, que transfere para o chefe político a autoridade e o interesse pelas coisas [...]". Sobre a questão regional, o Estado não só poderia como deveria incidir, consertando os erros desse condicionamento gerador de diversas das dinâmicas desagregadoras, como o caudilhismo, caciquismo e o personalismo dos grupos regionais e partidos políticos (ANDRADE, 1940, p. 104). Em relação a isso, a história ensinou que a resposta mais adequada às tendências localistas regionalistas foi a sistemática centralização do governo, como princípio de equilíbrio e neutralização dos regionalismos (ANDRADE, 1940, p. 107).

A menção seguinte ao tema do regionalismo vem quando ao falar das ondas políticas desencadeadas pela Revolução de 1930, Almir de Andrade deixa claro que o movimento teria sido acompanhado dos mais diversos ímpetos ideológicos da época, inclusive aqueles que eram seus inimigos eleitos, como a questão regionalista. $O$ autor afirma que, juntamente com paixões políticas caóticas, outras ambições regionalistas também foram acessas em meio à tocha de 1930 (ANDRADE, 1940, p. 121). Por sorte, o Estado Novo teria mitigado essas tendências adjacentes que corriam em paralelo ao movimento central.

Ao comemorar outra vitória do Regime sobre esse ímpeto regionalista, o autor chamaria atenção para a eliminação de determinados inimigos postos. Mais uma vez, o tema era analisado a partir de uma chave negativa, onde era dever do Estado eliminá-lo. Seriam eles:

[...] A política facciosa, em que as dedicações eleitorais eram pagas com favores onerosos; o provincialismo, que criava e multiplicava obstáculos ao livre curso dos 
valores econômicos; os particularismos, que estabeleciam preferências para a outorga de benefícios; as pretensões de hegemonias, que prejudicavam o bom entendimento de todos os brasileiros. (ANDRADE, 1940, p.185)

A partir desse momento, o Estado poderia lançar seu empenho no sentido da construção de uma nacionalidade forte e integrada. Mesmo assim, o autor faria a ressalva, que à nosso ver diferencia a crítica do localismo da crítica ao regionalismo. Seria extremamente problemático atacar os modos de expressão e manifestação cultural próprios de cada porção do país, dessa forma, Almir de Andrade faz a ressalva de que o empreendimento de moldação da nacionalidade não se trataria de um menosprezo das necessidades regionais, ou mesmo de uma transfiguração do organismo cultural brasileiro. Este seria um exemplo de centralização mal dirigida, justamente oposta à ação do estado plástico defendida pelo autor. Sendo assim, A centralização política deveria apenas "[...] exprimir a necessidade de dar unidade, orientação inteligente e objetivos comuns a todas as energias criadoras da sociedade" (ANDRADE, 1940, p. 218).

O papel do Estado Novo seria combater a intransigência federalista causadora da desagregação das iniciativas nacionais. A descentralização causada pelo fenômeno político seria contrária aos interesses nacionais. A orientação determinada pelo particularismo seria a face do regionalismo a ser combatida e, com a inteligência necessária, as possibilidades regionais seriam conduzidas em direção à comunhão nacional (ANDRADE, 1940, p. 219). O regionalismo como forma exacerbada de representação local entrou na linguagem crítica à Primeira República, já comum desde 1930, mas intensificada durante o Regime.

Almir de Andrade abordaria a questão regional novamente, mesmo que indiretamente, em um livro de sua organização. Em O pensamento político do presidente (1943), em trecho assinado por Silvio Peixoto, quando mais uma vez um autor chamaria atenção para necessidade de uma tradição política nacional unitária que afastasse os perigos de desagregação interna, não permitindo o mesmo tipo de revolução nativista comum no século $\mathrm{XIX}^{4}$ (ANDRADE, 1943, p. 50-51). Diferentemente dos autores trabalhados até o momento, Almir de Andrade admitiu que o mando localista e as tendências regionalistas são dados típicos da cultura social brasileira e não apenas um mal crônico a ser extirpado.

Os textos deste grupo de autores do Estado Novo recorreram frequentemente à análise de figuras fortes do século XIX e XX. Alguns citavam o controle parlamentar exercido por Lloyd George na liderança do Partido Liberal Inglês. Outros, como Cândido Mota Filho, referiram-se à ditadura disfarçada de Franklin Delano Roosevelt 5 . Mas todos concordam em um ponto fundamental: as contingências brasileiras demandariam a ação de um homem forte,

\footnotetext{
${ }^{4}$ No texto, intitulado Tradição política do princípio de unidade nacional, Silvio Peixoto trataria do tema da coesão nacional, assim como da necessidade de se manter através de medidas cautelosas, mas firmes, o seu caráter insolúvel.

${ }^{5}$ Este argumento pode ser encontrado em O Poder Executivo e as Ditaduras Constitucionais, livro de Cândido Mota Filho, publicado no ano de 1940.
} 
mas adaptado à realidade nacional. Desse modo, o nosso líder não seria o típico Europeu, mas o pai compreensivo de uma nação complexa, miscigenada, de dimensões continentais e repletas de distinções internas.

À altura de 1937, todos concordavam que o "homem forte" do regime seria Getúlio Dornelles Vargas. Como líder do movimento tenentista, exitoso em 1930, o então 14ํㅜㅇ Presidente do país havia obtido sucesso em suprimir ou eliminar os elementos rivais à sua posição dentro das fileiras vitoriosas. Apesar de ter se tornado o grande líder do Estado Novo, Vargas não deixaria de explicitar teórica e intelectualmente o seu projeto de governo. Cerca de um ano antes de O Pensamento Político do Presidente, de Almir de Andrade, o próprio havia publicado um livro com as balizas e direções do governo.

As diretrizes da nova política do Brasil (1942) revelaram os interesses do presidente do país com relação à política tanto interna quanto externa. A obra se dividiu em sete partes: Política Interna, Política Externa, Política Econômica, Política Social, Política Militar, Política Demográfica e Política Cultural. O tema do regionalismo é abordado nas seções sobre a Política Interna, Política Econômica, Política Demográfica e Política Cultural. Para efeitos de compreensão é interessante que abordemos de ponto em ponto.

No primeiro capítulo, o presidente inicia uma crítica ampla à configuração brasileira contemporânea. Ao abordar os diferentes graus de desenvolvimento de cada estado, o texto demonstra a incompatibilidade do novo regime com a diferenciação entre Estados fortes e Estado fracos, pelo menos no plano ideal. Tal tipo de classificação seria uma aberração frente ao regime adotado no pós 30 (VARGAS, 1942, p. 45). A política da União para com os estados deveria então ser marcada por um altruísmo capaz de suprimir os "egoísmos regionais". A União deveria aplicar os remédios adequados ao problema nacional e desse jeito apenas diferenciar entre as deficiências mais ao norte e mais ao sul (VARGAS, 1942, p, 46). No restante do capítulo, o autor chama atenção para o tipo de regionalismo que seria combatido pelo regime. Como guardião e protetor da tradição brasileira, o Estado Novo combateria apenas as preocupações regionais que interferissem no mundo da política, deixando de lado as manifestações culturais e maneirismos típicos. Nesse sentido, a luta do estado novo seria contra o caudilhismo, o localismo e o poder local, não propriamente ao regionalismo como fenômeno mais amplo.

Na seção de Política Econômica, Vargas menciona a questão regional ao falar da direção específica do imperialismo brasileiro. A ideia de que este deveria ser focado na dimensão interna, com a conquista do próprio território, e não com as guerras estrangeiras não seria demonstrada apenas nessa obra, mas em diversos outros textos de alguma forma conectados às figuras de suporte ao regime. Nesse sentido, nosso análogo à corrida para o

\footnotetext{
${ }^{6}$ Terminologia utilizada por quase todos autores do período.
} 
Oeste seria uma "marcha para o sertão", com o objetivo de civilizar as porções mais inabitadas e frear o urbanismo excessivo vivenciado à época (VARGAS, 1942, p. 131). Com isso, poderia ser construída uma rede de comunicação integrada nos ermos do país, unindo Norte e Sul (VARGAS, 1942, p. 179). Desse modo, a extinção da veleidade nacional se fez presente mais uma vez como uma preocupação para o Estado Novo, ao menos no campo das ideias.

Os outros dois tópicos apresentam uma abordagem mais curta do tema, com o autor tratando da Política Demográfica e Cultural do país. Na primeira, Getúlio Vargas compreende que a questão tanto do partidarismo faccioso, engendrado regionalmente, (VARGAS, 1942, p. 292) quanto a questão do povoamento de regiões extra sulistas seria fundamental para realização dos objetivos demográficos do Regime (VARGAS, 1942, p. 297). Quanto à Política Cultural, o presidente apresenta soluções para questão da diferenciação regional ao demonstrar o papel que o cinema pode ter como elemento de formação de um imaginário coletivo que fortaleça a integração nacional (VARGAS, 1942, p. 344).

Devido à sua relação de proximidade com Vargas, Almir de Andrade gozou de extrema influência durante os anos do Estado Novo e tornou-se, junto com o presidente, o maior portavoz da arquitetura do Regime. Ambos apresentaram uma visão mais amena e mediada sobre o tema do regionalismo, optando por ataques cada vez mais concentrados no campo político do espectro regional. Com isso, ambos cristalizam melhor o posicionamento do Governo em relação à realidade nacional. Posicionamento este que pode ser considerado moderado em relação aos demais nomes não envolvidos com a execução diária dos rumos da política governamental.

\section{Considerações finais}

O cacoete da aversão ao divisionismo foi tão forte ao longo dos anos de 1920 e 1930 que acabou sendo replicada pelos autores elogiosos ao regionalismo, como quando Gilberto Freyre afirma em seu discurso no I Congresso Brasileiro de Regionalismo, que o imperativo regional não se traduzia em um divisionismo político. Nele, o autor deixaria clara a separação entre o ímpeto regionalista e a tendência desagregadora que lhes foi imbuída por seus opositores. Isto nos ajuda a compreender em parte a constância na abordagem do tema do regionalismo por parte dos textos trabalhados.

Dado o período das obras analisadas, buscamos isolar regionalismo, sócio-cultural, do fenômeno da tendência estadualista, disputa política. Enquanto o segundo trata dos elementos próprios do mundo político, com o domínio parlamentar de interesses locais, o outro lida com uma dinâmica de disputas por hegemonia cultural na formação da nação. Os textos são bem-sucedidos em operar esta distinção, mas a análise mais acurada de suas complexidades demonstra a utilização de dois prismas para contemplação da questão. 
Após isso, podemos perceber que é justamente na cisão gerada por este prisma que existe uma maior diferença entre as figuras que circundavam o governo, fazendo parte esporadicamente de suas fileiras, dos nomes mais vinculados à arquitetura do Regime. Enquanto os textos satélites optam por ataques mais contundentes ao tema, os textos que expressariam uma visão mais oficial do Estado Novo optaram por uma abordagem mais moderada, chamando atenção para necessidade de uma melhor matização da questão regional. Tanto para Almir de Andrade, quanto para Getúlio Vargas, ficaria claro que o mundo da cultura não deveria ser um elemento passível de alteração, exceto em casos de exagero nas condutas deletérias localistas.

Outro elemento recorrente, observado ao longo das obras, foi a utilização dos vocábulos da crítica ao regionalismo excluindo ao centro nervoso do país. Apesar da configuração regional entre 1937 e 1945 ser diferente da atual, podemos perceber que os trechos fizeram, em sua maioria, referência ao Nordeste brasileiro. Também surgem críticas ao caudilhismo sulista, à confusão típica da organização do Centro-Oeste e ao esquecido Norte do país. Em momento algum, cita-se o Rio de Janeiro como um exemplo de regionalidade latente. Isto faz muito sentido na medida em que o Regime considerava a capital como a síntese da nacionalidade e berço do poder centralizado no país.

Neste momento, cabe às nossas futuras explorações tentar traçar o perfil dos textos das figuras que se viam fora do ciclo estado-novista, tentando perceber se há alguma diferença sensível na abordagem do tema da regionalidade ou se este foi realmente um tópus crítico hegemônico no pós-30 Para isso, precisaremos mapear trabalhos de nomes como Armando de Salles (1887-1945) e Virgílio de Mello Franco (1897-1948). Esta empreitada será sem dúvida o caminho natural a ser seguido pela presente exploração.

\section{Referências}

ALMEIDA, Martins de. Brasil Errado: ensaio político sobre os erros do Brasil como país. Rio de Janeiro: Civilização Brasileira Editora, 1932.

AMARAL, Azevedo. O Estado Autoritário e a Realidade Nacional. Brasília: UnB, 2002. AMARAL, Azevedo. Getúlio Vargas estadista. Rio de Janeiro: Irmãos Pongetti, 1941. AMARAL, Azevedo. Ordem e paz brasileiras. In: Os grandes problemas nacionais. Rio de Janeiro: DIP, 1942.

ANDRADE, Almir Bonfim. Força, Cultura e Liberdade: as origens históricas e tendências atuais da evolução política do Brasil. Rio de Janeiro: José Olympio, 1940.

ANDRADE, Almir Bonfim. O pensamento político do presidente. Rio de Janeiro. DIP, 1943. ARRAIS, Monte. O Estado Novo e as suas diretrizes: estudos políticos e constitucionais. Rio de Janeiro: José Olympio, 1938. 
CAMPOS, Francisco. O Estado Nacional: sua estrutura, seu conteúdo ideológico. Rio de Janeiro: José Olympio, 1941.

CUNHA, Euclydes da. Os Sertões. São Paulo: Editora Publifolha, 2000.

CUNHA, Euclydes da. Manifesto Regionalista. Recife: Instituto Joaquim Nabuco de Ciências Sociais, 1967.

DUARTE, Manuel. Doutrina contra doutrina. Rio de Janeiro: DIP, 1940.

HOLLIS, Martin. Meaning and context. Quentin Skinner and his critics. Princeton: Princeton University Press, 1988.

KOSELLECK, Reinhart. Futures Past: On the semantics of historical time. Cambridge: MIT Press, 1985.

KOSELLECK, Reinhart. The practice of conceptual history: Time history, spacing concepts. Stanford: Stanford University Press, 2002.

POCOCK, John Greville Agard. The Reconstruction of Discourse: Towards the Historiography of Political Thought. Comparative literature, dec. 1981.

POCOCK, John Greville Agard. Linguagens do ideário político. São Paulo: Edusp, 2003. Political Thought and History. Essays on Theory and Method. Cambridge: Cambridge University Press, 2009.

SANTOS, Wanderley Guilherme, LYNCH, Christian Edward Cyril (org.). A imaginação política brasileira: cinco ensaios de história intelectual. Rio de Janeiro: Revan, 2017.

SKINNER, Quentin. Meaning and understanding in the history of ideas. Nova Jersey: Wiley-Wesleyan University, 1969.

VARGAS, Getúlio Dornelles. As diretrizes da nova política do Brasil. Rio de Janeiro: José Olympio, 1942.

VIANNA, Francisco José de Oliveira. O Idealismo da Constituição. Rio de Janeiro: Companhia Editora Nacional, 1939.

VIANNA, Francisco José de Oliveira. Direito do Trabalho e Democracia Social. Rio de Janeiro: José Olympio, 1951. 